\title{
Timely Detection of Changes in the Meridional Overturning Circulation at $26^{\circ} \mathrm{N}$ in the Atlantic
}

\author{
Johanna Baehr and Helmuth HaAk \\ Max Planck Institute for Meteorology, Hamburg, Germany \\ Steven Alderson and Stuart A. Cunningham \\ National Oceanography Centre, Southampton, United Kingdom \\ Johann H. JungClaus And Jochem Marotzke \\ Max Planck Institute for Meteorology, Hamburg, Germany
}

(Manuscript received 18 September 2006, in final form 16 April 2007)

\begin{abstract}
It is investigated how changes in the North Atlantic meridional overturning circulation (MOC) might be reliably detected within a few decades, using the observations provided by the RAPID-MOC $26^{\circ} \mathrm{N}$ array. Previously, detectability of MOC changes had been investigated with a univariate MOC time series exhibiting strong internal variability, which would prohibit the detection of MOC changes within a few decades. Here, a modification of K. Hasselmann's fingerprint technique is used: (simulated) observations are projected onto a time-independent spatial pattern of natural variability to derive a time-dependent detection variable. The fixed spatial pattern of natural variability is derived by regressing the zonal density gradient along $26^{\circ} \mathrm{N}$ against the strength of the MOC at $26^{\circ} \mathrm{N}$ within the coupled ECHAM5/Max Planck Institute Ocean Model's (MPI-OM) control climate simulation. This pattern is confirmed against the observed anomalies found between the 1957 and the 2004 hydrographic occupations of the section. Onto this fixed spatial pattern of natural variability, both the existing hydrographic observations and simulated observations mimicking the RAPID-MOC $26^{\circ} \mathrm{N}$ array in three realizations of the Intergovernmental Panel on Climate Change (IPCC) scenario A1B are projected. For a random observation error of $0.01 \mathrm{~kg} \mathrm{~m}^{-3}$, and only using zonal density gradients between 1700- and 3100-m depth, statistically significant detection occurs with $95 \%$ reliability after about $30 \mathrm{yr}$, in the model and climate change scenario analyzed here. Compared to using a single MOC time series as the detection variable, continuous observations of zonal density gradients reduce the detection time by $50 \%$. For the five hydrographic occupations of the $26^{\circ} \mathrm{N}$ transect, none of the analyzed depth ranges shows a significant trend between 1957 and 2004, implying that there was no MOC trend over the past $50 \mathrm{yr}$.
\end{abstract}

\section{Introduction}

Numerous studies have analyzed the problem of detecting anthropogenic climate change (e.g., International Ad Hoc Detection and Attribution Group 2005). Most of these efforts have focused on air temperature observations, predominantly surface air temperature, but some studies have analyzed the vertical structure of

Corresponding author address: Johanna Baehr, Massachusetts Institute of Technology, Dept. of Earth, Atmospheric, and Planetary Sciences, Room 54-1517, 77 Massachusetts Ave., Cambridge, MA 02139-4307.

E-mail: baehr@mit.edu

DOI: 10.1175/2007JCLI1686.1

(C) 2007 American Meteorological Society temperature in the atmosphere. In contrast, a rigorous detection analysis of oceanic quantities has found considerably less attention. Notable exceptions are Santer et al. (1995), who conducted a univariate and multivariate detection study for several integrated ocean variables, Barnett et al. (2001) and Reichert et al. (2002), who analyzed global ocean heat content, and Banks and Bindoff (2003), who analyzed temperature and salinity changes in the Indo-Pacific. The attribution of observed oceanic changes to human origin has recently been made by Barnett et al. (2005).

One of the quantities eminently associated with past and future climate change is the oceanic meridional 
overturning circulation (MOC; National Research Council 2002), the zonally and vertically - from the surface to a given depth-integrated meridional flow as a function of latitude and depth; in the following denoted as (univariate) MOC time series. Several modeling studies suggest that the MOC is potentially sensitive to anthropogenic climate change (Manabe and Stouffer 1994; Mikolajewicz and Voss 2000; Cubasch et al. 2001; Thorpe et al. 2001; Gregory et al. 2005). A weakening or collapse of the Atlantic MOC is expected to entail a reduction in the North Atlantic heat transport, leading to a significant cooling over the North Atlantic and its adjacent regions (Manabe and Stouffer 1994; Vellinga and Wood 2002).

Ship-based transoceanic sections yield the most reliable observational estimates of the MOC (e.g., Hall and Bryden 1982; Ganachaud and Wunsch 2000; Bryden et al. 2005b), but deliver snapshots only. Recently, an observing array to monitor the MOC at $26^{\circ} \mathrm{N}$ in the Atlantic was deployed (Marotzke et al. 2002; Schiermeier 2004). This RAPID-MOC array is based on the Marotzke et al. (1999) conceptual study, suggesting that the MOC could be continuously monitored using measurements of the density at the eastern and western boundaries of a zonal section. The deployed array consists of nine full water column profiles of density and ocean bottom pressure along $26^{\circ} \mathrm{N}$, with dense coverage at the western and eastern boundaries and additional moorings at both sides of the Mid-Atlantic Ridge (Rayner and Cunningham 2005). Prior to deployment, the array was tested in two numerical models (Hirschi et al. 2003; Baehr et al. 2004), showing that such an array could be capable of capturing both the mean value of the MOC as well as the short-term variability. Further simulations showed that the array is capable of detecting long-term trends within several decades based on the analysis of a (univariate) MOC time series in the employed model (Baehr et al. 2007).

More generally, potential MOC changes were considered in the framework of a rigorous detection analysis: Vellinga and Wood (2004) identified-based on a formal optimization-about 15 locations for potential temperature and salinity observations, supplementing the $26^{\circ} \mathrm{N}$ RAPID-MOC array, which would-in the Third Hadley Centre Coupled Ocean-Atmosphere GCM (HadCM3) - reduce the detection time for MOC changes to a decade. Keller et al. (2007) found that an observing system based on hydrographic transects every five years [with an observation uncertainty of about 5 Sverdrups (Sv)] is likely to result in detection of changes in the maximum MOC before a point of no return is reached. Brennan et al. (2007) found that in the Commonwealth Scientific and Industrial Research
Organisation (CSIRO) model, MOC detection times can be reduced by $40 \%$, if in addition to a (univariate) MOC time series apparent oxygen utilization is measured along $26^{\circ}$ N. Santer et al. (1995), Banks and Wood (2002), Vellinga and Wood (2004), and Baehr et al. (2007) found that the detection times on a (univariate) MOC time series are on the order of several decades to a century. Thus, Santer et al. (1995), Barnett et al. (2001), and Banks and Wood (2002) suggested that the (multivariate) analysis of subsurface structures generally have the potential to deliver shorter detection times.

Several (observable) quantities have been proposed to deliver information about MOC changes with a higher signal-to-noise ratio than the actual meridional transports (e.g., Hu et al. 2004; Latif et al. 2004; Levermann et al. 2005). These studies-as the present one-shared the difficulty of having to disentangle the change in a certain property and MOC changes. They did not consider the observation of transport series, but the observation of the chosen property, thus relying for the link between MOC changes and the change in a certain property on a numerical model.

Here, we present a detection variable for the MOC, which is, in contrast to earlier studies: (i) based on a dynamical link between an observable quantity and the MOC, and therefore not relying on the correlations in a specific model, and (ii) solely based on observable quantities, that is, the zonal density gradient at $26^{\circ} \mathrm{N}$. This detection variable provides timely detection of MOC changes at $26^{\circ} \mathrm{N}$, that is, faster detection than when relying on a (univariate) MOC time series alone. More specifically, we simulate observations, as a substitute for ongoing and future observational efforts, to test whether the $26^{\circ} \mathrm{N}$ RAPID-MOC observing array has the potential to deliver timely information about future MOC changes.

In contrast to earlier studies (e.g., Santer et al. 1995; Baehr et al. 2007), we use a detection variable that takes the spatial structure of the simulated observations into account. The derivation of a suitable detection variable follows to a large extent the methodology established by Hasselmann $(1979,1993)$ and Hegerl et al. (1996), although we deviate from it: we project (simulated) observations onto an observable pattern (modelbased, but confirmed against observations) that represents natural variability, in contrast to projecting observations on a model-based pattern that represents an assumed future change. Here we ask whether an observed signal is outside the range of natural variability, in contrast to the question of whether an observed signal is along an expected pattern of change. The formal estimation of the detection time follows the approach 
of Santer et al. (1995), with the modifications used by Baehr et al. (2007).

This paper is organized as follows: in section 2 we describe the observations and model output used in the present study. Section 3 focuses on the comparison of hydrographic observations and model output. Section 4 describes the detection method and the resulting detection times. In section 5, we discuss the results, and conclusions are given in section 6 .

\section{Data}

\section{a. Observations}

The $26^{\circ} \mathrm{N}$ transatlantic section has been occupied five times-in 1957, 1981, 1992, 1998, and 2004 (Fuglister 1960; Roemmich and Wunsch 1985; Parrilla et al. 1994; McTaggert et al. 1999; Cunningham 2005)-although the exact latitudes, start, and end points of the occupations differ (cf. Cunningham and Alderson 2007). For these five occupations, we calculate the detection variables, following the same procedure as for the model output. Further, we compare directly the 1957 and 2004 occupations. For the analysis of the 2004 occupation, additional long-term current meter measurements of the Deep Western Boundary Current (DWBC) were available (Lee et al. 1990, 1996; Fillenbaum et al. 1997; Bryden et al. 2005a).

The 1957 data were obtained from discrete water samples at approximately 25 depths, while from 1981 onward temperature and salinity profiles were obtained from conductivity-temperature-depth (CTD) stations with discrete salinity samples being measured against standard seawater, and used for calibration of the CTD salinities. Salinities from 1957 contain a systematic salinity error between 0.004 and 0.006 (Bryden et al. 1996; Arbic and Owens 2001), compared to a measured range between about 33 and 37.5. This makes 1957 salinities unreliable below 2000 dbar (Arbic and Owens 2001), but the qualitative characteristics of intermediate and thermocline waters are unaffected.

\section{b. Model description and analyzed output}

In the present study, we use model output from the coupled ECHAM5/MPI-OM global climate model (Roeckner et al. 2003; Marsland et al. 2003). The atmospheric component ECHAM5 is coupled to the ocean component MPI-OM, and no flux adjustments are applied. ECHAM5 is realized at T63 resolution with 31 vertical levels. MPI-OM is realized on an orthogonal curvilinear C-grid (Marsland et al. 2003). The northern grid pole is shifted to Greenland, avoiding the singu- larity at the geographical North Pole. MPI-OM's average horizontal resolution is about $1.5^{\circ}$, varying between $12 \mathrm{~km}$ close to Greenland and $180 \mathrm{~km}$ in the tropical Pacific. The vertical resolution is realized on 40 nonequidistant $z$ levels, of which 20 are distributed over the top $700 \mathrm{~m}$. The bottom topography is resolved by partial grid cells. Jungclaus et al. (2006b) described the coupled model's ocean mean state, based on an unperturbed control simulation and forced with present-day greenhouse gas concentrations.

We analyze model output of ECHAM5/MPI-OM's ocean component from a control simulation and an ensemble of three realizations forced by the same climate change greenhouse gas scenario. The unperturbed control simulation has a length of $460 \mathrm{yr}$, and applies preindustrial greenhouse gas concentrations. The climate change experiments are part of a suite of experiments performed for the Intergovernmental Panel on Climate Change (IPCC) Fourth Assessment Report. The three realizations start from different years of the control run, and have a length of $340 \mathrm{yr}$ each. For the years 1860 2000 , the simulations are forced with observed greenhouse gas concentrations and aerosol concentrations from preindustrial to present-day values. For the years 2001-2100, the simulations are forced with greenhouse gas concentrations based on the IPCC Special Report on Emissions Scenarios (SRES) emission scenario A1B (Nakicenovic and Swart 2000); $\mathrm{CO}_{2}$ concentrations rise from $380 \mathrm{ppmv}$ in the year 2001 to $700 \mathrm{ppmv}$ in the year 2100. Over the same period, global mean surface temperature rises by $3.8 \mathrm{~K}$ by the year 2100 , relative to 1961-1990. The North Atlantic MOC at $30^{\circ} \mathrm{N}$ weakens in the A1B scenario from $18.5 \mathrm{~Sv}$ to about $11 \mathrm{~Sv}$ by the year 2100 (Jungclaus et al. 2006a). For the years 21012199 , the simulations apply greenhouse concentrations fixed at the levels of the year 2100 .

\section{c. Simulation of monitoring array}

We "deploy" an oceanic monitoring system into the numerical model ECHAM5/MPI-OM, allowing us to test various characteristics of the simulated observations. The observing system simulated here resembles the existing RAPID-MOC array at $26^{\circ} \mathrm{N}$ in the Atlantic (Marotzke et al. 2002). As the deployed observing array, the simulated array is based on continuous measurements of density, with intensified coverage of the eastern and western boundaries (Rayner and Cunningham 2005). The number of simulated full-depth moorings (nine in total) is similar to the deployed RAPIDMOC array (nine full-depth moorings). In accordance with the real RAPID-MOC array, surface wind stress is assumed to be known from satellite measurements. The 
direct transport estimates in the Florida Strait, which the real array incorporates, are-because of the absence of a geographically confined Florida Strait in the model-substituted with assumed western boundary current observations. In both the real and the simulated array the obtained zonal density gradients are used to infer meridional transports (Hirschi et al. 2003; Baehr et al. 2004). The dynamical background of the observing array has been extensively analyzed in Marotzke et al. (1999); Hirschi et al. (2003); Baehr et al. (2004); Hirschi and Marotzke (2007). The setup employed in the present study is identical to the one used in Baehr et al. (2007). All simulated measurements are assumed to be taken as monthly means, but annual means are formed, and only these are analyzed.

\section{Results from data-model comparison}

Comparing hydrographic observations and model simulations, we derive a fixed spatial pattern of natural variability, from which in turn a range of natural variability is derived. Subsequently, we use this range of natural variability to determine when a significant change in the simulated observations of a climate change scenario can be detected.

\section{a. Observations versus model}

First, we compare directly the 1957 and 2004 hydrographic observations of the $26^{\circ} \mathrm{N}$ transect, similarly to Cunningham and Alderson (2007). Specifically, we compare the differences in potential temperature and salinity between the two occupations (2004-1957) for the eastern and western boundaries, and the zonal mean (Fig. 1). Most notably, intermediate and thermocline waters become warmer and more saline, while the lower NADW cools and freshens. These changes are more pronounced at the western boundary. The difference in meridional transports associated with this temperature and salinity difference is a decrease of the northward transport shallower than $1000 \mathrm{~m}$ by about $8 \mathrm{~Sv}$, and a decrease in the southward transport between 3000 and $5000 \mathrm{~m}$ depth of about $8 \mathrm{~Sv}$ (Bryden et al. 2005b).

To compare the observed transport variations between 1957 and 2004 with the transport variability in the ECHAM5/MPI-OM control simulation, we perform a regression analysis for the model output. Temperature and salinity fields are regressed against the strength of the MOC at $1000 \mathrm{~m}$. The standard deviation of the MOC in the control simulation is about $1 \mathrm{~Sv}$ (for annual mean values), whereas the transports observed in 1957 and 2004 indicated a variation of 8 Sv (Bryden et al. 2005b); for details see the preceding paragraph). We therefore multiply the anomaly patterns of the regression analysis by $-8 \mathrm{~Sv}$. Away from the surface (i.e., below about 250-m depth) the regression reveals similar anomaly patterns as the observations (Fig. 2).

In both the observed and modeled temperature anomalies a weakening of the MOC is associated with a warming of the intermediate waters, mostly at the western but also at the eastern boundary (Figs. 1 and 2). Similarly, intermediate waters become significantly saltier at the western boundary, and, to a lesser extent, at the eastern boundary. The upper NADW becomes slightly warmer, while the lower NADW cools and freshens (Figs. 1 and 2). Note that in the model, the NADW starts at a shallower depth, and upper and lower NADW are not readily distinguished. In the model, an MOC decrease is associated with higher temperature and salinity below a $2500-\mathrm{m}$ depth, while the observed anomalies indicate cooling and freshening. At the surface, the profiles based on the regression do not seem to be very reliable because of the high variability of the surface waters, and the fact that the regression is done versus the strength of the MOC at a 1000-m depth. Although the modeled and observed temperature and salinity fields differ in the deeper ocean, the differences have somewhat compensating effects on density. In summary, comparing the temperature and salinity patterns associated with MOC variability in both the observations and ECHAM5/MPI-OM's control simulation shows similar anomaly patterns. The results suggest that the observed changes in temperature and salinity can be associated with variations in the MOC, which are within the model's range of natural variability. We therefore use the temperature and salinity fields resulting from a regression with the MOC in the control simulation to describe the range of natural variability.

\section{b. Selection of a suitable quantity for detection}

Having analyzed MOC variability and its relation to temperature and salinity variations in the control simulation, we investigate how this relation behaves under a climate change scenario, in order to identify a suitable variable for the detection of MOC changes at $26^{\circ} \mathrm{N}$.

Under the employed climate change scenario, temperature and salinity characteristics at the eastern and western boundaries change considerably (Fig. 3). At the western boundary, thermocline and intermediate waters become warmer and more saline (Fig. 3a), while at the eastern boundary, thermocline and intermediate waters become warmer, but not generally more saline (Fig. 3b). Changes are less pronounced in the deep 

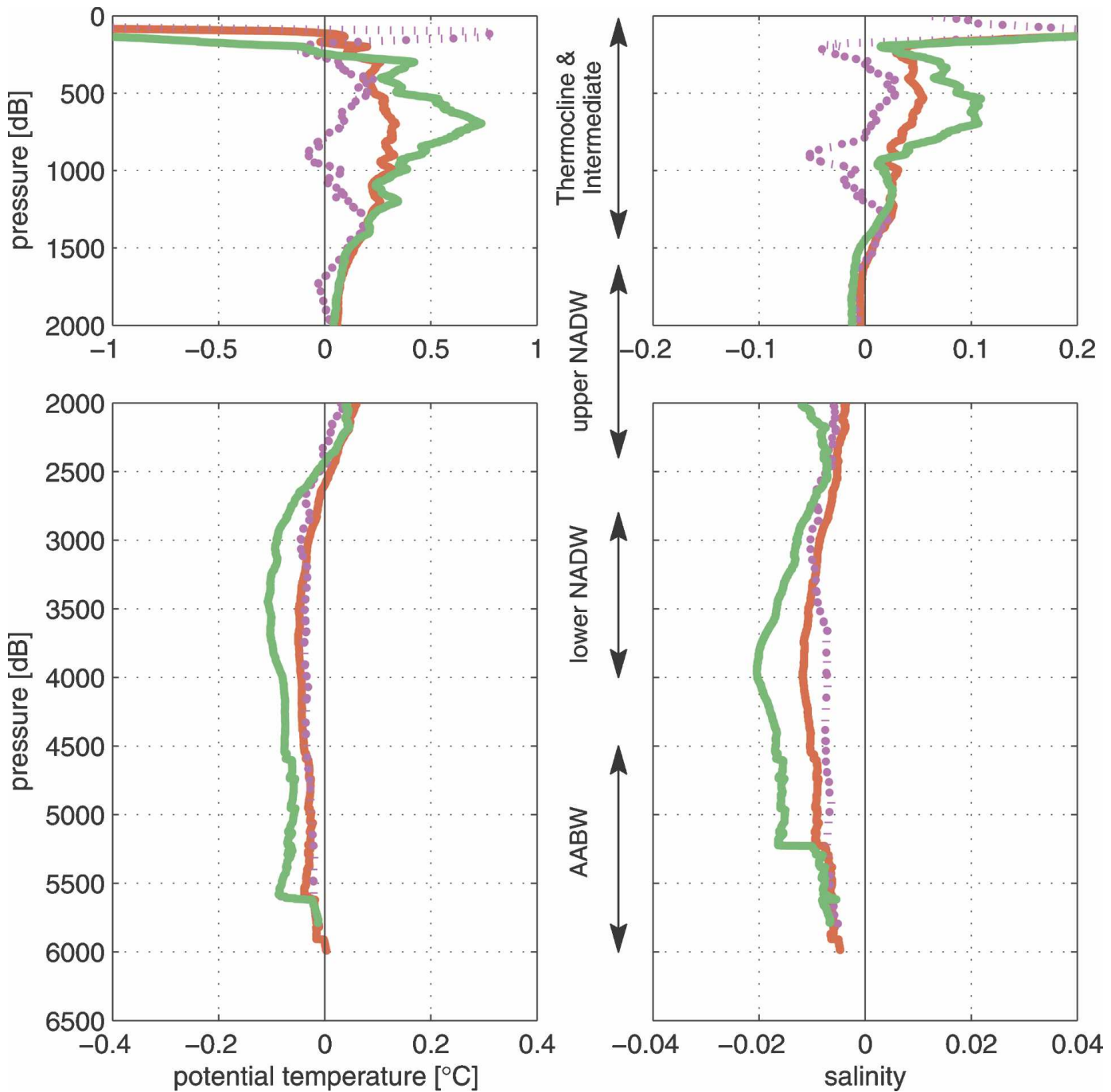

FIG. 1. (left) Observed potential temperature $\left({ }^{\circ} \mathrm{C}\right.$ ) and (right) salinity (PSU) difference between the 2004 and the 1957 occupations. The western boundary extends from $65^{\circ}$ to $75^{\circ} \mathrm{W}$ (green), the eastern boundary from $25^{\circ}$ to $35^{\circ} \mathrm{W}$ (red), and the zonal average from $15^{\circ}$ to $100^{\circ} \mathrm{W}$ (magenta, dotted).

ocean. Overall, analyzing the eastern and western boundaries independently yields predominantly the global warming signal (for both the eastern and the western boundary, and for temperature as well as salinity; i.e., the water becomes more saline). Changes in the zonally average temperature and salinity fields are dominated by the influence of the western boundary; thermocline and intermediate waters become warmer and more saline, which is again the global warming signal (Fig. 3c).

Detecting changes in the MOC requires a careful differentiation between density changes related to an MOC change, and small-scale or short-term density changes, which do not entail an MOC change. To identify a suitable variable for the detection of MOC changes, we analyze the zonal density gradient (Fig. 3d), changes in which are intimately linked to changes in the MOC. If the flow is everywhere in thermal wind balance, for example, in the presence of vertical sidewalls, the vertical structure of the MOC is proportional to the east-west density gradient.

Based on this relationship, Marotzke (1997) and Marotzke and Klinger (2000) developed the theory of a purely buoyancy-driven flow. The presence of wind forcing and irregular bottom topography, that is, more realistic circumstances, leads to a time-varying Ekman contribution (Lee and Marotzke 1998; Jayne and Marotzke 2001) and the external mode (Robbins and Toole 1997; Lee and Marotzke 1998), respectively, neither of which is in thermal wind balance. However, 

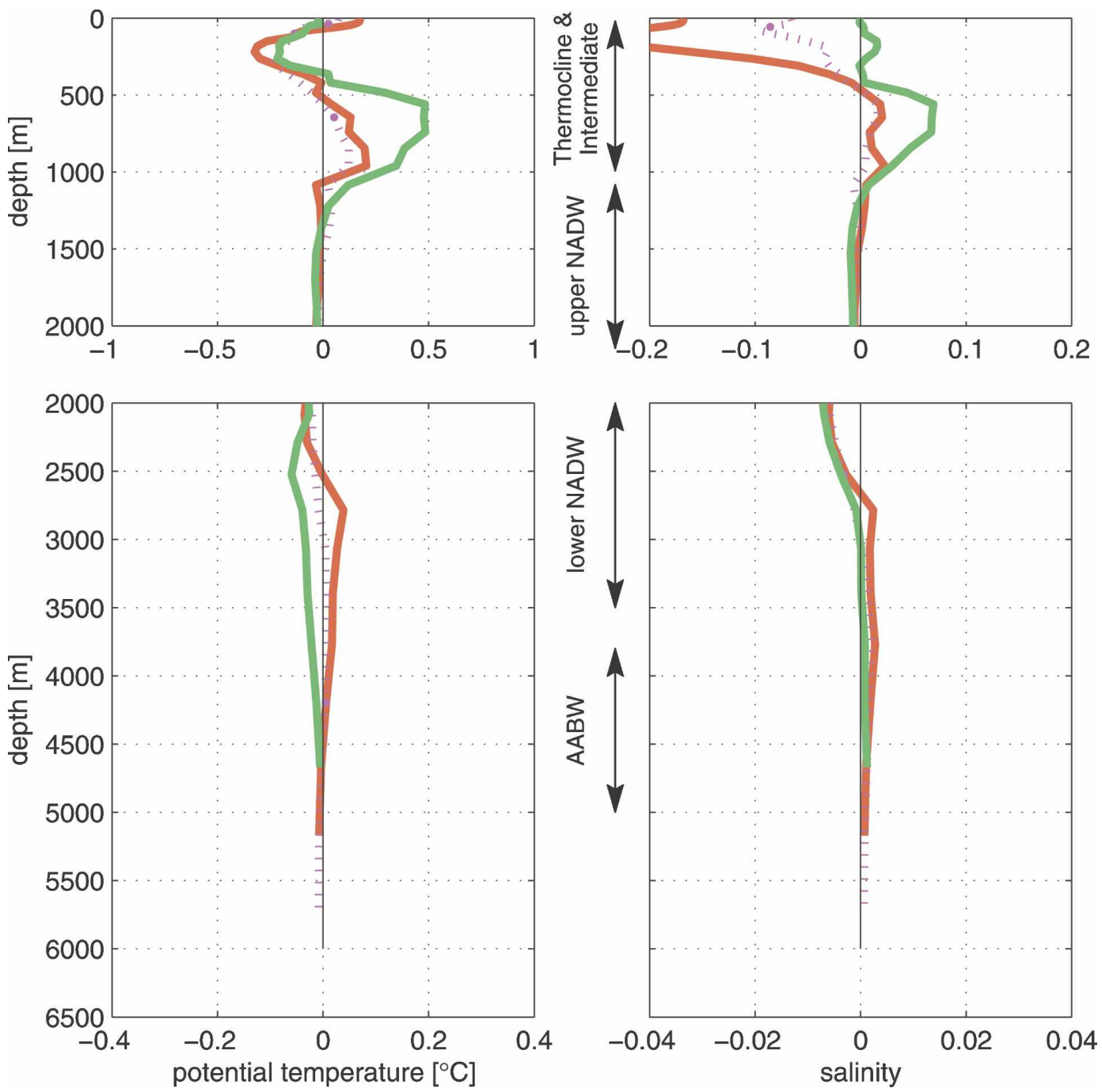

FIG. 2. (left) Modeled potential temperature $\left({ }^{\circ} \mathrm{C}\right)$ and (right) salinity (PSU) anomaly patterns of regression against MOC in the ECHAM5/MPI-OM control simulation, multiplied by $-8 \mathrm{~Sv}\left(1 \mathrm{~Sv}=10^{6} \mathrm{~m}^{3} \mathrm{~s}^{-1}\right)$, that is, the transport variation inferred from the observed temperature and salinity fields (Bryden et al. 2005b). The western boundary extends from $70^{\circ}$ to $80^{\circ} \mathrm{W}$ (green), the eastern boundary from $26^{\circ}$ to $36^{\circ} \mathrm{W}$ (red), and the zonal average from $15^{\circ}$ to $80^{\circ} \mathrm{W}$ (magenta, dotted).

Köhl (2005) and Hirschi and Marotzke (2007) showed that the thermal wind and the Ekman contribution are the dominant contributions to the MOC in the North Atlantic. Density anomalies influence the meridional transports, once the anomalies reach the boundaries of the basin (Marotzke et al. 1999), suggesting that the density changes close to the ocean margin are sufficient to capture the basinwide velocity shear (Hirschi and Marotzke 2007). Further, the zonal density gradient is less influenced by the direct global warming signal: changes in the zonal density gradient occur throughout the water column (Fig. 3d). In the following, we will therefore use the zonal density gradient as a measure of the strength of the MOC.

\section{Detection analysis}

The RAPID-MOC array provides continuous measurements of zonal density gradients and related meridional transports at $26^{\circ} \mathrm{N}$. It has not been established whether these measurements allow for a timely detection of MOC changes: an analysis based on a (univariate) MOC time series suggests that detection times might be in the order of several decades to a century, depending on the observation error (Baehr et al. 2007). Here, we follow Santer et al. (1995) and define "detection time" as the earliest time at which an anthropogenic change can be detected with statistical significance $(p<0.05)$. 

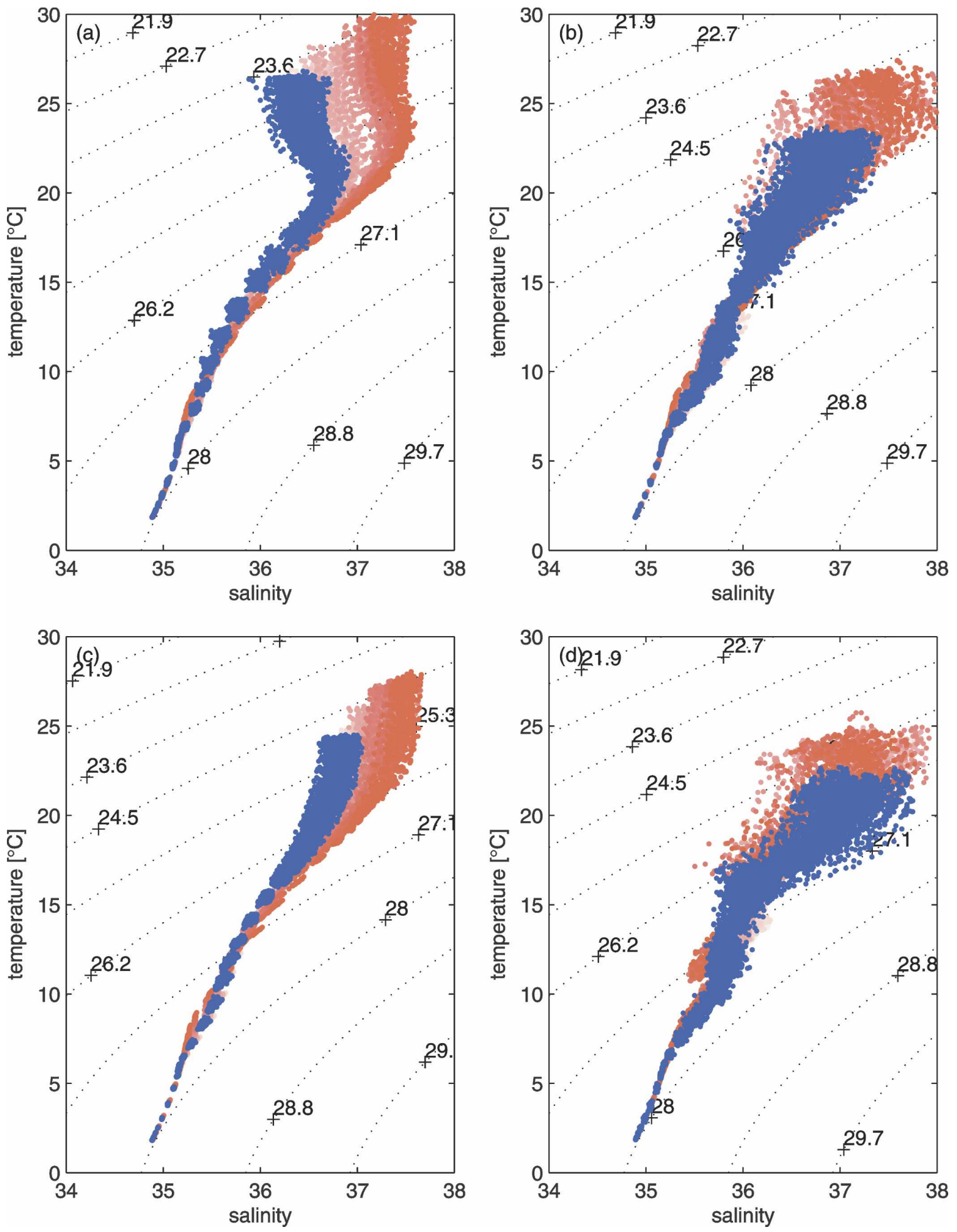

FIG. 3. Temperature $\left({ }^{\circ} \mathrm{C}\right.$ )-salinity (PSU) diagrams: (a) western boundary, (b) eastern boundary, (c) zonal mean, and (d) eastern boundary minus western boundary plus vertical profile of time-mean difference. Each panel represents annual mean values for control simulation (blue) and global warming simulation (red) over full depth range. Shading of red markers indicates time, the darker the shading the later the time step. Contour lines indicate lines of constant potential density. The western boundary extends from $70^{\circ}$ to $80^{\circ} \mathrm{W}$, the eastern boundary from $26^{\circ}$ to $36^{\circ} \mathrm{W}$, and the zonal average from $15^{\circ}$ to $80^{\circ} \mathrm{W}$. 


\section{a. Detection method}

In contrast to the univariate analysis of Baehr et al. (2007), a multivariate analysis that includes the twodimensional spatial information provided by the RAPID-MOC array, has the potential to result in earlier detection. A multivariate analysis requires, first, the derivation of a univariate detection variable and, second, the specification of the detection time. We derive a detection variable following Hasselmann $(1979,1993)$ and subsequently perform a formal detection analysis following Santer et al. (1995), as modified by Baehr et al. (2007).

\section{1) Detection variable}

Hasselmann (1979) proposed to project a multidimensional detection space onto a smaller number of variables by forming a scalar product with fixed spatial patterns. Hasselmann $(1979,1993)$ discussed the multifingerprint case, whereas Hegerl et al. (1996) discussed a simplified version of Hasselmann's technique for a single fingerprint. The climate change signal, a space-time-dependent variable, is considered as the climate vector $\boldsymbol{\Psi}$ in the detection space. In the notation of Hegerl et al. (1996), the single scalar-detection variable $d$ is a result of projecting $\boldsymbol{\Psi}$ onto a suitably chosen fingerprint $\mathbf{f}: d=\mathbf{f}^{\mathrm{T}} \boldsymbol{\Psi}$, with the fingerprint $\mathbf{f}$ representing the expected pattern of climate change.

Here, we project the selected variable of the climate vector $\boldsymbol{\Psi}$ (denoted $\boldsymbol{\Psi}_{\mathbf{f}}$ to indicate the forced simulation) onto a fixed spatial pattern of natural variability $\tilde{\mathbf{N}}$. In contrast to Hasselmann (1979, 1993), Barnett (1991), and Hegerl et al. (1996), the observations $\left(\boldsymbol{\Psi}_{\mathbf{f}}\right)$ are not projected to an expected pattern of climate change, but to an observable time-independent pattern of natural variability. Therefore, we do not ask whether an observed signal is along an expected pattern of change. Instead, we ask whether an observed signal is outside the range of natural variability. The advantage of a fixed spatial pattern of natural variability over an expected pattern of climate change is that the first can be based on observations, while the second will always depend on the employed model. The projection yields the time-dependent detection variable $d_{f}$ for the forced simulation

$$
d_{f}(t)=\tilde{\mathbf{N}}^{\mathrm{T}}(x, z) \boldsymbol{\Psi}_{\mathbf{f}}(t, x, z) .
$$

Here $\Psi_{\mathbf{f}}(t, x, z)$ consists of the values of a selected variable depending on time $(t)$, the longitude $(x)$, and the vertical $(z)$ dimension. In further deviation from Hasselmann $(1979,1993)$ and Hegerl et al. (1996), we analyze the detection variable $d_{f}(t)$, that is, without projecting the observations to an optimized fingerprint.
If $d_{f}(t)$ exhibits no trend, the observed climate signal is within the given range of natural variability, whereas a trend in $d_{f}(t)$ indicates a deviation of the observed climate signal from the natural variability.

In the present study, the climate vector $\boldsymbol{\Psi}_{\mathbf{f}}(t, x, z)$ is represented as the density field $\rho_{f}(t, x, z)$, measured by the RAPID-MOC monitoring array along the zonal transect at $26^{\circ} \mathrm{N}: \boldsymbol{\Psi}_{\mathbf{f}}(t, x, z)=\rho_{f}(t, x, z)$, where the time mean of the control simulation is subtracted.

\section{2) FIXED SPATIAL PATTERN OF NATURAL VARIABILITY}

The fixed spatial pattern of natural variability $\tilde{\mathbf{N}}$ is represented by a regression between the simulated density measurements, $\rho_{c}(t, x, z)$, and the strength of the MOC, $\operatorname{MOC}_{c}(t)$, both within the control simulation with $n_{t}$ time steps, where the overbar marks the time average:

$$
\tilde{\mathbf{N}}(x, z)=\frac{\sum_{t=1}^{n_{t}}\left[\mathrm{MOC}_{c}(t)-\overline{\mathrm{MOC}_{c}}\right]\left[\rho_{c}(t, x, z)-\overline{\rho_{c}(x, z)}\right]}{n_{t} \sigma_{\mathrm{MOC}_{c}}},
$$

yielding the estimated fixed spatial pattern of natural variability $\tilde{\mathbf{N}}(x, z)$, that is, the part of the density field related to MOC variability. Here $\sigma_{\mathrm{MOC}_{c}}$ is the standard deviation of the MOC in the control run. Note that we normalize the fixed spatial pattern of natural variability $\tilde{\mathbf{N}}$ to unity before computing the detection variable, allowing comparison of different detection variables with respect to their different signal and noise content. For the employed model, $\tilde{\mathbf{N}}$ was shown to be comparable to observations (section $3 \mathrm{a}$ ).

\section{3) BOUNDS OF NATURAL VARIABILITY}

Similarly to the forced simulation, the timedependent behavior of the detection variable $d_{c}$ is estimated for the control simulation, projecting the selected variable of the climate vector $\boldsymbol{\Psi}_{c}$ onto $\tilde{\mathbf{N}}$ :

$$
d_{c}(t)=\tilde{\mathbf{N}}^{\mathrm{T}}(x, z) \mathbf{\Psi}_{c}(t, x, z) .
$$

We use $d_{c}(t)$ to derive the upper and lower bounds of the natural variability, which are subsequently used to determine the detection time for $d_{f}(t)$. Again, the fixed spatial pattern of natural variability is normalized before computing the detection variable, and temporalbut not spatial-anomalies are used. To avoid a bias in the statistics of the detection variable $d_{c}$, we use independent data to estimate the fixed spatial pattern of natural variability $\tilde{\mathbf{N}}$ and the climate vector $\boldsymbol{\Psi}_{c}$. The 
control simulation is divided into two simulations of 230-yr length each, using the first half to estimate $\tilde{\mathbf{N}}$ and the second half to estimate $\boldsymbol{\Psi}_{c}$.

To derive the upper and lower bounds of the natural variability, a bootstrap analysis is conducted for the detection variable $d_{c}(t)$, allowing subsequently for Monte Carlo sampling of different realizations of observation error. Generally, $d_{c}(t)$ can be treated similarly to the univariate time series analyzed in Baehr et al. (2007). However, some differences arise in adding observational uncertainty to the simulated measurements. To present a self-consistent description of the method here, we provide the full detection algorithm. To the components forming the control detection variable, random observation error $\varepsilon_{\rho}$ is added for $n_{b}$ different realizations before the intrinsic bootstrap analysis is performed:

$$
d_{c}\left(t, n_{b}\right)=\tilde{\mathbf{N}}^{\mathrm{T}}(x, z)\left[\boldsymbol{\Psi}_{c}(t, x, z)+\varepsilon_{\rho}\left(t, n_{b}, x, z\right)\right],
$$

and the bootstrap analysis is conducted for a range of length of observation periods $l$, each starting at a different random starting point $t^{*}$, yielding a detection variable $d_{c}^{*}\left(l, n_{b}\right)$, depending on $l$ and the number of different realizations $n_{b}$ :

$$
d_{c}^{*}\left(l, n_{b}\right)=d_{c}\left(t^{*}: t^{*}+l, n_{b}\right) .
$$

This detection variable can subsequently be treated like a univariate time series: linear trends $p^{*}\left(l, n_{b}\right)$ are estimated by a least squares fit for each of these bootstrap samples. For each length of observation period, the upper- and lower-bound confidence limits $\left[c_{\text {lower }}(l)\right.$ and $\left.c_{\text {upper }}(l)\right]$ are estimated following standard practice ap- plied normally distributed samples. We use $\alpha=0.05$. The natural variability is then described by an interval of linear trends $\left[c_{\text {lower }}(l), c_{\text {upper }}(l)\right]$.

\section{4) Changes IN THE FORCED RUN}

Similarly to the control simulation, we estimate trends in the forced simulation, which can be used to test whether the forced run has left the range of natural variability given by the control simulation. To include observational uncertainty into the detection variable $d_{f}(t)$, we again add random observation error to Eq. (1):

$$
d_{f}\left(t, n_{b}\right)=\tilde{\mathbf{N}}^{\mathrm{T}}(x, z)\left[\boldsymbol{\Psi}_{\mathbf{f}}(t, x, z)+\varepsilon_{\rho}\left(t, n_{b}, x, z\right)\right],
$$

and conduct a bootstrap analysis for a range of length of observation periods, which all start at the same fixed starting point $t_{\text {start }}$ :

$$
d^{*}\left(l, n_{b}\right)=d\left[t=t_{\text {start }}:\left(t=t_{\text {start }}\right)+l, n_{b}\right] .
$$

Linear trends $p_{f}^{*}\left(l, n_{b}\right)$ are estimated by least squares fit for each length of observation period and for all bootstrap samples.

\section{5) Detection time}

The estimate of the detection time is identical to the algorithm used for the univariate time series analyzed in Baehr et al. (2007). To estimate the detection time, we first derive the times, $t_{\text {det }}$, where the linear trends $p_{f}^{*}\left(l, n_{b}\right)$ in the forced run have left the given range of natural variability, that is, the interval of linear trends in the control run $\left[c_{\text {lower }}(l), c_{\text {upper }}(l)\right]$, with $(1-\alpha / 2)$ reliability:

$$
t_{\text {det }}(t)= \begin{cases}t_{\text {start }}+l, & \text { if } \frac{\sum_{i=1}^{n_{b}} I\left\{\left[p_{f}^{*}(l, i)<c_{\text {lower }}(l)\right]\right\}}{n_{b}} \geq 1-\frac{\alpha}{2} \\ t_{\text {start }}+l, & \text { if } \frac{\sum_{i=1}^{n_{b}} I\left\{\left[p_{f}^{*}(l, i)>c_{\text {upper }}(l)\right]\right\}}{n_{b}} \geq 1-\frac{\alpha}{2} \\ 0, & \text { otherwise }\end{cases}
$$

where $I$ is the indicator function with argument $a$, which is equal to 1 if its argument is true, and zero otherwise:

$$
I(a)=\left\{\begin{array}{lll}
1, & \text { if } \quad a=\text { true } \\
0, & \text { if } \quad a=\text { false } .
\end{array}\right.
$$

We denote as detection time, $t_{D}$, the minimum $(>0)$ of $t_{\text {det }}$ :

$$
t_{D}=\min \left\{t_{\mathrm{det}}\right\},
$$

that is, the first time at which the forced run has left the range of natural variability, given by the control run, with $95 \%$ reliability.

\section{b. Results of the detection analysis}

We simulate the continuous observations of density with the RAPID-MOC array at $26^{\circ} \mathrm{N}$, as described in section 2c. Initially, we consider an observing system 

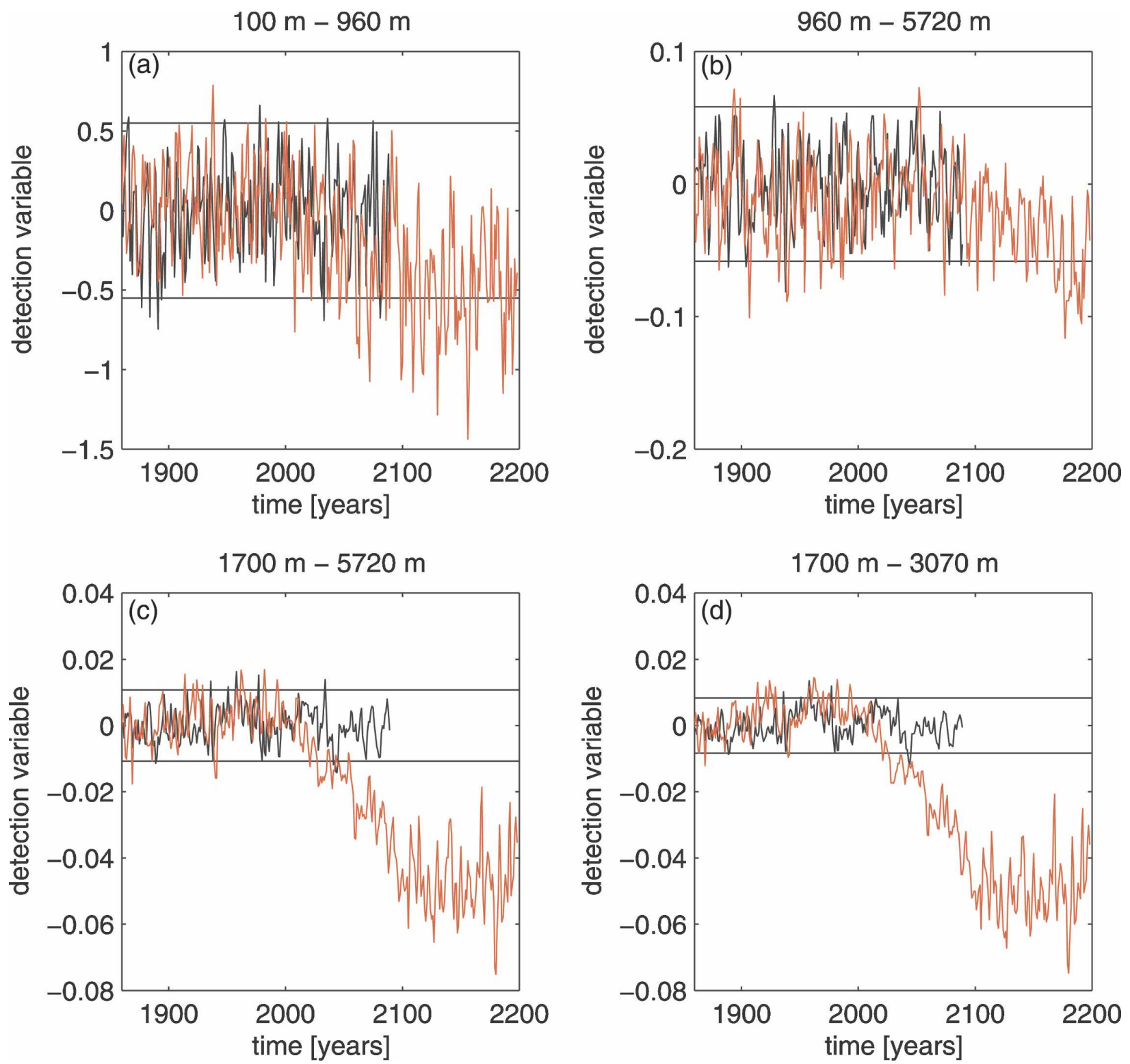

FIG. 4. Detection variables for the forced simulation (red) and control simulation (black) over different depths: (a) 100-960 m, (b) $1000 \mathrm{~m}$-bottom $(5720 \mathrm{~m}$ ), (c) $1700 \mathrm{~m}$-bottom, and (d) 1700-3100 m. The indicated upper and lower limits of the control detection variable (horizontal black lines) correspond to $\pm 1.96 \mathrm{std}$ dev of $d_{c}$. The detection variable is based on zonal density gradients, eastern boundary minus western boundary. The boundaries extend from $70^{\circ}$ to $80^{\circ} \mathrm{W}$ (western boundary) and $26^{\circ}$ to $36^{\circ} \mathrm{W}$ (eastern boundary).

without observation error. The detection variables for the forced simulation $\left[d_{f}(t)\right]$, and the control simulation $\left[d_{c}(t)\right]$ are calculated following Eqs. (1) and (3), respectively (Fig. 4). We average $\tilde{\mathbf{N}}$ and the climate vector $\boldsymbol{\Psi}_{\mathbf{f}}$ or $\boldsymbol{\Psi}_{c}$, respectively, over the eastern and western boundaries (as used in Figs. 2 and 4), and subtract the resulting profiles from each other, before computing the detection variables.

Depending on the depth over which the detection variable for the forced simulation is computed, the signal-to-noise ratio varies significantly. If the full water column (over the full transect) is considered, no trend is visible (not shown). A weak trend is apparent if the strongly varying top $100 \mathrm{~m}$ of the water column are left out (Fig. 4a). Note that constraining the analysis to the top $1000 \mathrm{~m}$ of the water column or considering the full depth (below $100 \mathrm{~m}$ ) does not significantly change the shape of the detection variable. Between 500 and 1000 $\mathrm{m}$, waters warm and freshen significantly, with compensating effects on the density difference (cf. Fig. 3d). Considering the water column between $1000 \mathrm{~m}$ and the bottom does not enhance the signal (Fig. 4b), whereas 

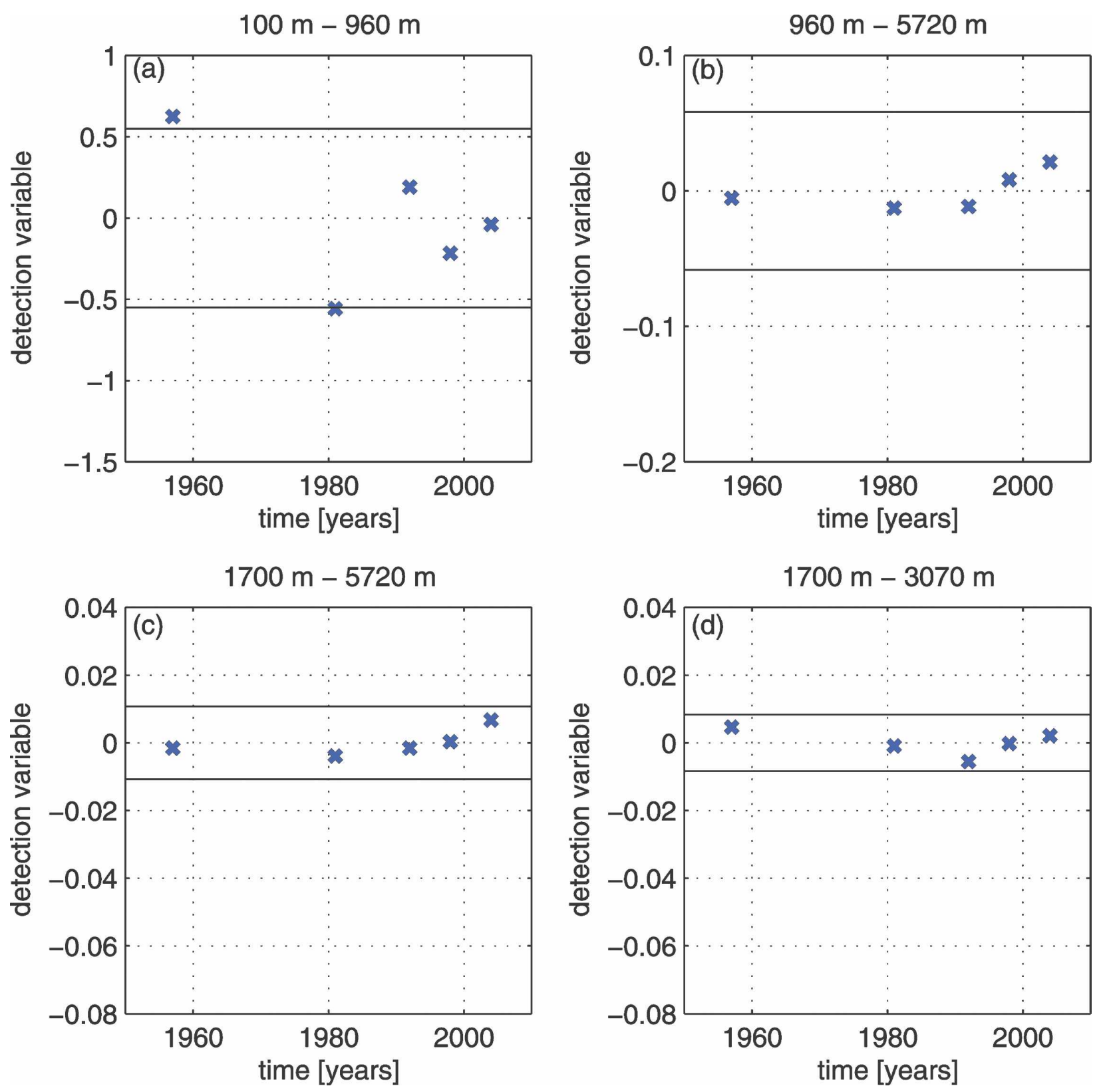

FIG. 5. Detection variables for hydrographic occupations of $26^{\circ} \mathrm{N}$ over different depth ranges: (a) 100-960 m, (b) $1000 \mathrm{~m}-$ bottom $(5720 \mathrm{~m}),(\mathrm{c}) 1700 \mathrm{~m}$-bottom, and (d) 1700-3100 m. The indicated upper and lower limits of the control detection variable (horizontal black lines) correspond to $\pm 1.96 \mathrm{std}$ dev of $d_{c}$; identical to the confidence limits shown in Fig. 4. The detection variable is based on zonal density gradients, eastern boundary minus western boundary. The boundaries extend from $65^{\circ}$ to $75^{\circ} \mathrm{W}$ (western boundary) and $25^{\circ}$ to $35^{\circ} \mathrm{W}$ (eastern boundary).

the zonal density gradient shows a strong decrease at depths between $1700 \mathrm{~m}$ and the bottom (Fig. 4c). Most of this signal is found between 1700 and $3100 \mathrm{~m}$ (Fig. 4d). While the zonal gradient in salinity decreases with time throughout the water column, temperature differences are mainly constrained to the top $2000 \mathrm{~m}$. The detection variable computed in Fig. $4 \mathrm{~d}$ is therefore dominated by haline changes in the zonal density gra- dient. However, neither the detection variable derived from zonal salinity gradient nor temperature gradient alone provides a reliable estimate of the zonal density gradient.

For comparison with the modeling results, the corresponding detection variable based on the five hydrographic occupations of the $26^{\circ} \mathrm{N}$ transect are calculated (Fig. 5). The observed detection variable is the result of 
projecting the observed zonal density gradient onto the fixed spatial pattern of natural variability provided by the control simulation of the model ( $\tilde{\mathbf{N}})$, Eq. (2). Note that again, we compute the detection variable based on anomalies by subtracting the time mean over all observations from the individual observations. Comparing the same depth ranges as used in Fig. 4, we find that none of the analyzed depth ranges shows a significant trend between 1957 and 2004 (Fig. 5), implying no MOC trend over the past $50 \mathrm{yr}$.

To conduct a formal detection analysis, the detection algorithm described in section 4 is applied. We add observation error to the detection variable derived from the simulated observations. For both $d_{c}^{*}\left(l, n_{b}\right)$ and $d^{*}\left(l, n_{b}\right)$ we use $n_{b}=10^{3}$ realizations of the respective observation uncertainty (identically, independently, and normally distributed random noise) of different magnitudes. We use identical magnitudes for $\varepsilon_{\rho}\left(n_{b}\right)$ in the control and forced simulations, for example, $0.005 \mathrm{~kg} \mathrm{~m}^{-3}$ (standard deviation). This error estimate includes observation errors as well as the sampling and discretization errors being associated with measuring temperature, salinity, and pressure (to obtain density) at different instruments, that is, different discrete depths, on a mooring; $0.005 \mathrm{~kg} \mathrm{~m}^{-3}$ is a realistic error estimate (Kanzow 2004; Kanzow et al. 2006).

The detection times, computed following Eq. (10), differ considerably between the different depth ranges (Table 1). Considering the full water column with only leaving out the top $100 \mathrm{~m}$ results in a detection time ( $95 \%$ reliability) of around $60 \mathrm{yr}$. This detection time is reduced by about $50 \%$ if the analysis concentrates on the range between 1700 and $3100 \mathrm{~m}$. Different magnitudes of observation error have little influence on the detection times (Table 1). For comparison, the detection time resulting from the analysis of a (univariate) MOC time series was about $60 \mathrm{yr}$ for an observation error of $1 \mathrm{~Sv}$ (Baehr et al. 2007).

\section{Discussion}

To derive a detection variable for anthropogenic MOC changes, we use-in deviation from Hasselmann (1979, 1993) and Hegerl et al. (1996) — a fixed spatial pattern of natural variability onto which we project the (simulated) observations. Therefore, we do not make any assumption about the anticipated long-term change in the underlying pattern. The employed fixed spatial pattern of natural variability is sought to be available from real observations (though not yet at present), whereas the selection of a suitable guess pattern (as in, e.g., Hegerl et al. 1996) is inherently dependent on the
TABLE 1. Detection time (95\% upper confidence limit; in years) for different observation errors and zonal density gradients over different depths. The three numbers represent the three realizations of the forced run.

\begin{tabular}{cccc}
\hline \hline & \multicolumn{3}{c}{ Observation error } \\
\cline { 2 - 4 } Depth range & $\begin{array}{c}\varepsilon_{\rho}=0.005 \\
\mathrm{~kg} \mathrm{~m}^{-3}\end{array}$ & $\begin{array}{c}\varepsilon_{\rho}=0.01 \\
\mathrm{~kg} \mathrm{~m}^{-3}\end{array}$ & $\begin{array}{c}\varepsilon_{\rho}=0.015 \\
\mathrm{~kg} \mathrm{~m}^{-3}\end{array}$ \\
\hline $100-960 \mathrm{~m}$ & $59,36,11$ & $60,36,11$ & $60,37,11$ \\
$100-5720 \mathrm{~m}$ & $60,45,11$ & $59,48,11$ & $60,51,11$ \\
$960-5720 \mathrm{~m}$ & $75,46,57$ & $92,52,61$ & $93,58,61$ \\
$1700-5720 \mathrm{~m}$ & $30,36,31$ & $47,36,37$ & $59,36,42$ \\
$1700-3070 \mathrm{~m}$ & $25,10,30$ & $29,11,30$ & $39,12,35$ \\
\hline
\end{tabular}

quality of the chosen model. Note that our fixed spatial pattern of natural variability $\tilde{\mathbf{N}}$ [as described by Eq. (2)] does not represent the full climate noise; although no formal truncation level is derived from any formal statistical algorithm, the regression analysis discards most of the noise, and enhances the signal. In further deviation from Hegerl et al. (1996), we do not use linear trends to represent the time dependence of the climate signal in the detection variable. We do, however, approximate the climate signal with linear trends over varying lengths of time intervals, when computing the detection time, following Santer et al. (1995) and Baehr et al. (2007).

We use our fixed spatial pattern of natural variability to test independently whether the certain (simulated) observations have left the given range of natural variability, that is, whether an MOC change is detected in the respective (simulated) observations. Having extracted the pattern of natural variability in the observations, and having confirmed our model-based fixed spatial pattern of natural variability against observations (section 3a) allows us to conduct this test for both the forced model simulation and the observations. Analyzing the forced model simulation suggests that the detection variable is sensitive to anthropogenic forcing (Fig. 4), and anthropogenic changes in the MOC can be detected within a couple of decades (Table 1). Repeating the analysis for the existing observations (Bryden et al. 2005b) suggests that the observed variations in the density field and its associated meridional transports are within the model's natural variability (Fig. 5).

Instead of considering zonal density gradients, that is, a different quantity than the MOC itself, we have initially investigated including additional information at several depths, that is, the vertically unintegrated meridional transports. Both an optimal fingerprint following, for example, Hegerl et al. (1996), and the method introduced in section 4a detect changes in the MOC after about $70 \mathrm{yr}$ (in the given climate change scenario, 
not shown), whereas the analysis of a (univariate) MOC time series results in detection times of about 60 yr Baehr et al. (2007). It is only seemingly paradoxical that the optimal fingerprint results in later detection than the analysis of a (univariate) MOC time series. Correlations between the zonally integrated transports at different depths are very low. Vertical integration acts as averaging, and results in higher correlation coefficients between adjacent depths; this in turn, yields smaller detection times for a single-integrated-MOC time series than a suite of meridional transport time series.

We show that the detection times depend largely on the chosen depth range. So far, we have based the choice of the depth ranges on physical intuition rather than a formal signal-to-noise optimization technique, as some aspects of the model solution are not thought to represent the real ocean circulation in its full complexity. Following Hasselmann (1979, 1993), Hegerl et al. (1996) would imply an optimization of the fixed spatial pattern of natural variability before projecting observations onto it. We have taken some inceptive steps toward an optimization of the fixed spatial pattern of natural variability, but have not found significant improvement. Continuative investigations are necessary to establish whether Hasselmann's $(1979,1993)$ technique for an optimized fingerprint applied to a fixed spatial pattern of natural variability can significantly improve detection times.

We find little dependence of the detection times on the chosen observation error added to the zonal density gradient (Table 1). We have, however, not included any observational uncertainty in the estimate of the fixed spatial pattern of natural variability. While it would be desirable to include uncertainty in the MOC estimate, it would result in multiplying two random numbers [Eq. (6)], which in turn would result in a detection variable that is not normally distributed. Including observational uncertainty to the MOC estimate alone, and not to the simulated density measurements, results in somewhat increased detection times (not shown).

Although we use three simulations of a climate change scenario, and find the results to be robust across these realizations, the conclusions are still dependent on the particular model employed with respect to both the actual magnitude of the detection times and the reliable separation of the global warming signal and MOC changes. Repeating the analysis in different models might reduce the sensitivity of the detection times to model uncertainty, while ultimately this test is to be repeated relying purely on observations. Similarly, it would be interesting to repeat the separation of the global warming signal and MOC changes in other mod- els to test whether (i) the physical underpinning of the estimate of the fixed spatial pattern of natural variability (cf. section 3b), and (ii) the consistency with observations (cf. section 3a) is found to be robust.

A further question is whether additional observations allow for a faster detection. In part, Vellinga and Wood (2004) addressed this question using optimal fingerprints. In a next step, Vellinga and Wood's (2004) findings could be combined with the results of the present study, that is, testing whether the addition of another latitude improves detection times. However, to apply the resulting conclusions to the real ocean, further knowledge about the dynamics of potential MOC changes is needed in addition to the formal detection analysis. This investigation of the propagation of the MOC signal and the coherence of the MOC cell are beyond the scope of this paper, and the assessment of additional observations to improve the detection time is therefore left for future study.

\section{Conclusions}

Based on our analysis of the five hydrographic occupations of the $26^{\circ} \mathrm{N}$ transect, and our simulated MOC and density observations in the particular solutions of ECHAM5/MPI-OM, we conclude the following:

1) The variations in existing density observations and related meridional transports at $26^{\circ} \mathrm{N}$ (Bryden et al. $2005 \mathrm{~b}$ ) are within the model's range of natural variability.

2) Using a realizable set of observations, a reliable detection variable for anthropogenic MOC change can be derived by projecting (simulated) observations onto a suitably chosen observed representation of the natural variability, displaying a fixed spatial pattern.

3) Zonal density gradients at $26^{\circ} \mathrm{N}$ yield a reliable detection variable for $\mathrm{MOC}$ changes at $26^{\circ} \mathrm{N}$. Observations limited to the eastern or the western boundary, or either the salinity or the temperature field alone, are not capable of delivering this information.

4) For zonal density gradients between 1700 and 3100 $\mathrm{m}$ at $26^{\circ} \mathrm{N}$, with an assumed observation error of $0.01 \mathrm{~kg} \mathrm{~m}^{-3}$, the detection time (95\% reliability) is about $30 \mathrm{yr}$; a reduction by about $50 \%$, compared to using a (univariate) MOC time series.

Acknowledgments. We thank Klaus Hasselmann, Reiner Schnur, and the two reviewers for helpful comments on the manuscript. This work was supported by the Max Planck Society (JB, HH, JJ, JM). The computer simulations were performed at the Deutsches 
Klimarechenzentrum (DKRZ) in Hamburg, Germany. The 2004 transatlantic hydrographic section along $25^{\circ} \mathrm{N}$ was supported by the Natural Environment Research Council as part of the Core Strategic Research Programme "Ocean Variability and Climate" at the Southampton Oceanography Centre. Analysis of the five sections along $25^{\circ} \mathrm{N}$ was also supported by NERC as part of the RAPID Programme.

\section{REFERENCES}

Arbic, B. K., and W. B. Owens, 2001: Climate warming of Atlantic intermediate waters. J. Climate, 14, 4091-4108.

Baehr, J., J. Hirschi, J. Beismann, and J. Marotzke, 2004: Monitoring the meridional overturning circulation in the North Atlantic: A model-based array design study. J. Mar. Res., 62, 283-312.

_- K. Keller, and J. Marotzke, 2007: Detecting potential changes in the meridional overturning circulation at $26^{\circ} \mathrm{N}$ in the Atlantic. Climatic Change, doi:10.1007/s10584-006-9153-z.

Banks, H., and R. Wood, 2002: Where to look for anthropogenic climate change in the ocean. J. Climate, 15, 879-891.

— ture and salinity changes in the Indo-Pacific from the coupled climate model HadCM3: Processes and mechanisms. J. Climate, 16, 156-166.

Barnett, T. P., 1991: An attempt to detect the greenhouse-gas signal in a transient GCM simulation. Greenhouse-GasInduced Climatic Change: A Critical Appraisal of Simulations and Observations, M. E. Schlesinger, Ed., Elsevier Science, 559-568.

- D. W. Pierce, and R. Schnur, 2001: Detection of anthropogenic climate change in the world's oceans. Science, 292, 270274.

, - - K. M. Achutarao, P. J. Gleckler, B. D. Santer, J. M. Gregory, and W. M. Washington, 2005: Penetration of human-induced warming into the world's oceans. Science, 309, 284-287.

Brennan, C. E., R. J. Matear, and K. Keller, 2007: Measuring oxygen concentrations improves the detection capabilities of an ocean circulation observation array. J. Geophys. Res., in press.

Bryden, H. L., M. J. Griffiths, A. M. Lavin, R. C. Millard, G. Parrilla, and W. M. Smethie, 1996: Decadal changes in water mass characteristics at $24^{\circ} \mathrm{N}$ in the subtropical North Atlantic. J. Climate, 9, 3162-3186.

— W. W. Johns, and P. M. Saunders, 2005a: Deep western boundary current east of Abaco: Mean structure and transport. J. Mar. Res., 63, 35-57.

- H. R. Longworth, and S. A. Cunningham, 2005b: Slowing of the Atlantic meridional overturning circulation at $25^{\circ} \mathrm{N}$. $\mathrm{Na}$ ture, 438, 655-657.

Cubasch, U., and Coauthors, 2001: Projections of future climate change. Climate Change 2001: The Scientific Basis, J. T. Houghton et al., Eds., Cambridge University Press, 526-582.

Cunningham, S. A., 2005: RRS Discovery Cruise D279 04 Apr-10 May 2004: A transatlantic hydrography section at $24.5^{\circ} \mathrm{N}$. Southampton Oceanography Centre Cruise Rep. 54, 199 pp. , and S. Alderson, 2007: Transatlantic temperature and salinity changes at $24.5^{\circ} \mathrm{N}$ from 1957 to 2004. Geophys. Res. Lett., 34, L14606, doi:10.1029/2007GL029821.
Fillenbaum, E. R., T. N. Lee, W. E. Johns, and R. J. Zantopp, 1997: Meridional heat transport variability at $26.5^{\circ} \mathrm{N}$ in the North Atlantic. J. Phys. Oceanogr., 27, 153-174.

Fuglister, F. C., 1960: Atlantic Ocean Atlas of Temperature and Salinity Profiles and Data from the International Geophysical Year of 1957-1958. Woods Hole Oceanographic Institution, $209 \mathrm{pp}$.

Ganachaud, A., and C. Wunsch, 2000: Improved estimates of global ocean circulation, heat transport and mixing from hydrographic data. Nature, 408, 453-457.

Gregory, J. M., and Coauthors, 2005: A model intercomparison of changes in the Atlantic thermohaline circulation in response to increasing atmospheric $\mathrm{CO}_{2}$ concentration. Geophys. Res. Lett., 32, L12703, doi:10.1029/2005GL023209.

Hall, M. M., and H. L. Bryden, 1982: Direct estimates and mechanisms of ocean heat transport. Deep-Sea Res., 29, 339-359.

Hasselmann, K., 1979: On the signal-to-noise problem in atmospheric response studies. Meteorology over the Tropical Oceans, D. B. Shaw, Ed., Royal Meteorological Society, 251259.

__ 1993: Optimal fingerprints for the detection of timedependent climate change. J. Climate, 6, 1957-1971.

Hegerl, G., H. von Stroch, K. Hasselmann, B. D. Santer, U. Cubasch, and P. D. Jones, 1996: Detecting greenhouse-gasinduced climate change with an optimal fingerprint. J. Climate, 9, 2281-2306.

Hirschi, J., and J. Marotzke, 2007: Reconstructing the meridional overturning circulation from boundary densities and zonal wind stress. J. Phys. Oceanogr., 37, 743-763.

_ J. Baehr, J. Marotzke, J. Stark, S. Cunningham, and J.-O. Beismann, 2003: A monitoring design for the Atlantic meridional overturning circulation. Geophys. Res. Lett., 30, 1413, doi:10.1029/2002GL016776.

Hu, A., G. A. Meehl, and W. Han, 2004: Detecting thermohaline circulation changes from ocean properties in a coupled model. Geophys. Res. Lett., 31, L13204, doi:10.1029/2004GL020218.

International Ad Hoc Detection and Attribution Group, 2005: Detecting and attributing external influences on the climate system: A review of recent advances. J. Climate, 18, 12911314.

Jayne, S. R., and J. Marotzke, 2001: The dynamics of ocean heat transport variability. Rev. Geophys., 39, 385-411.

Jungclaus, J. H., H. Haak, M. Esch, E. Roeckner, and J. Marotzke, 2006a: Will Greenland melting halt the thermohaline circulation? Geophys. Res. Lett., 33, L17708, doi:10.1029/ 2006GL026815.

—, M. Botzet, H. Haak, J. Luo, M. Latif, J. Marotzke, U. Mikolajewicz, and E. Roeckner, 2006b: Ocean circulation and tropical variability in the coupled model ECHAM5/ MPI-OM. J. Climate, 19, 3952-3972.

Kanzow, T., 2004: Monitoring the integrated deep meridional flow in the tropical North Atlantic. Ph.D. thesis, ChristianAlbrechts-Universität Kiel, 140 pp.

_ U. Send, W. Zenk, A. D. Chave, and M. Rhein, 2006: Monitoring the integrated deep meridional flow in the tropical North Atlantic: Long-term performance of a geostrophic array. Deep-Sea Res. I, 53, 528-546.

Keller, K., C. Deutsch, M. G. Hall, and D. F. Bradford, 2007: Early detection of changes in the North Atlantic meridional overturning circulation: Implications for the design of ocean observation systems. J. Climate, 20, 145-157.

Köhl, A., 2005: Anomalies of meridional overturning: Mecha- 
nisms in the North Atlantic. J. Phys. Oceanogr., 35, 14551472.

Latif, M., and Coauthors, 2004: Reconstructing, monitoring, and predicting multidecadal-scale changes in the North Atlantic thermohaline circulation with sea surface temperature. J. Climate, 17, 1605-1614.

Lee, T., and J. Marotzke, 1998: Seasonal cycles of meridional overturning and heat transport of the Indian Ocean. J. Phys. Oceanogr., 28, 923-943.

Lee, T. N., W. Johns, R. Zantopp, and F. Schott, 1990: Western boundary current structure and variability east of Abaco, Bahamas at $26.5^{\circ}$ N. J. Phys. Oceanogr., 20, 446-466.

,,$-- \ldots$, and E. R. Fillenbaum, 1996: Moored observations of western boundary current variability and thermohaline circulation at $26.5^{\circ} \mathrm{N}$ in the subtropical North Atlantic. $J$. Phys. Oceanogr., 26, 962-983.

Levermann, A., A. Griesel, M. Hoffmann, M. Montoya, and S. Rahmstorf, 2005: Dynamic sea level changes following changes in the thermohaline circulation. Climate Dyn., 24, 347-354.

Manabe, S., and R. J. Stouffer, 1994: Multiple-century response of a coupled ocean-atmosphere model to an increase of atmospheric carbon dioxide. J. Climate, 7, 5-23.

Marotzke, J., 1997: Boundary mixing and the dynamics of threedimensional thermohaline circulations. J. Phys. Oceanogr., 27, 1713-1728.

, and B. A. Klinger, 2000: The dynamics of equatorially asymmetric thermohaline circulations. J. Phys. Oceanogr., 30, 955970

— , R. Giering, K. Q. Zhang, D. Stammer, C. Hill, and T. Lee, 1999: Construction of the adjoint MIT ocean general circulation model and application to Atlantic heat transport sensitivity. J. Geophys. Res., 104, 29 529-29 547.

—, S. A. Cunningham, and H. L. Bryden, 2002: Monitoring the Atlantic meridional overturning circulation at $26.5^{\circ} \mathrm{N}$. Southampton Oceanography Centre, RAPID-MOC Initiative Proposal NER/T/S/2002/00481, 8 pp. [Available online at http://www.noc.soton.ac.uk/rapidmoc/.]

Marsland, S. J., H. Haak, J. H. Jungclaus, M. Latif, and F. Röske, 2003: The Max-Planck-Institute global ocean/sea ice model with orthogonal curvilinear coordinates. Ocean Modell., 5, 91-127.

McTaggert, K. E., G. C. Johnson, C. I. Fleurant, and M. O. Baringer, 1999: $\mathrm{CTD} / \mathrm{O}_{2}$ measurements collected on a Climate and Global Change cruise along $24^{\circ} \mathrm{N}$ in the Atlantic Ocean (WOCE section A6) during January-February 1998. NOAA/
Pacific Marine Environmental Laboratory Data Rep. ERL PMEL-68 (PB99-155194, Contribution 2056, 368 pp.

Mikolajewicz, U., and R. Voss, 2000: The role of individual air-sea flux components in $\mathrm{CO}_{2}$-induced changes of the ocean's circulation and climate. Climate Dyn., 16, 627-642.

Nakicenovic, N., and R. Swart, Eds., 2000: Emissions Scenarios. Cambridge University Press, 570 pp.

National Research Council, 2002: Abrupt Climate Change: Inevitable Surprises. National Academy Press, $230 \mathrm{pp}$.

Parrilla, G., A. Lavin, H. Bryden, M. Garcia, and R. Millard, 1994: Rising temperatures on the subtropical North Atlantic Ocean over the past 35 years. Nature, 369, 48-51.

Rayner, D., and S. A. Cunningham, 2005: RRS Discovery Cruise D277/D278: RAPID mooring cruise report February-March 2004. Southampton Oceanography Centre Cruise Rep. 53, 103 pp.

Reichert, B. K., R. Schnur, and L. Bengtsson, 2002: Global ocean warming tied to anthropogenic forcing. Geophys. Res. Lett., 29, 1525, doi:10.1029/2001GL013954.

Robbins, P. E., and J. M. Toole, 1997: The dissolved silica budget as a constraint on the meridional overturning circulation of the Indian Ocean. Deep-Sea Res. I, 44, 879-906.

Roeckner, E., and Coauthors, 2003: The atmospheric general circulation model ECHAM5, Part I: Model description. Max Planck Institute for Meteorology Tech. Rep. 349, 140 pp.

Roemmich, D., and C. Wunsch, 1985: Two transatlantic sections: Meridional circulation and heat flux in the subtropical North Atlantic Ocean. Deep-Sea Res., 32, 619-664.

Santer, B. D., U. Mikolajewicz, W. Brüggemann, U. Cubasch, K. Hasselmann, H. Höck, E. Maier-Reimer, and T. L. Wigley, 1995: Ocean variability and its influence on the detectability of greenhouse warming signals. J. Geophys. Res., 100, 10693 10725.

Schiermeier, Q., 2004: Gulf Stream probed for early warnings of system failure. Nature, 427, 769.

Thorpe, R. B., J. M. Gregory, T. C. Johns, R. A. Wood, and J. F. B. Mitchell, 2001: Mechanisms determining the Atlantic thermohaline circulation response to greenhouse gas forcing in a non-flux-adjusted coupled climate model. J. Climate, 14, 3102-3116.

Vellinga, M., and R. A. Wood, 2002: Global climatic impacts of a collapse of the Atlantic thermohaline circulation. Climatic Change, 54, 251-267.

_ and - 2004: Timely detection of anthropogenic change in the Atlantic meridional overturning circulation. Geophys. Res. Lett., 31, L14203, doi:10.1029/2004GL020306. 